\title{
Studi Penentuan Tingkat Pelayanan Irigasi Dengan Metode MASSCOTE Berdasarkan Rapid Appraisal Procedure (RAP) Sebagai Penunjang Keputusan Kinerja Irigasi Daerah Irigasi Makam Sukowono Kabupaten Jember
}

\author{
Titania Intan Permatasari $^{1 *}$, Rini Wahyu Sayekti ${ }^{1}$, M Janu Ismoyo ${ }^{1}$ \\ ${ }^{1}$ Jurusan Teknik Pengairan, Fakultas Teknik, Universitas Brawijaya, \\ JI. MT. Haryono no. 167, Malang, 65145, Indonesia \\ *Korespondensi Email: titaniaintanp@gmail.com
}

\begin{abstract}
Assesment Performance based on Permen PUPR No. 12/PRT/2015 is a indicator to description irrigation system management made to the 6 (six) parameters including; Physical Infrastructure, Plant Productivity, Supporting Facilities, Personnel Organization, Documentation and Water User Association (P3A), whereas the assessment is carried out by evaluation method of MASSCOTE with Rapid Appraisal Procedure (RAP) which is a set of systematic procedures to diagnose obstacles, performance and level services in the system irrigation to 4 (four) main indicators include; Service Indicator, P3A Indicator, Human Resource of Operator Indicator, and Channel Operations Modernization indicator, performance assessment are taken by surveyor of respondents Operator irrigation, and farmers P3A, Show performance index by Permen PUPR No. 12/PRT/2015 gave the value $64.22 \%$ which has Less Well Performance Operations and Maintenance of Makam Sukowono Irrigation, while the MASSCOTE methode show Performance 2,99 in level of Service which has Less Well Performance of Service and Operations Irrigation Channels. Based on the path analysis found significant influence with 4 (four) main indicator variables $\mathrm{X}_{1}, \mathrm{X}_{2}, \mathrm{X}_{3}$ and $\mathrm{X}_{4}$ to irrigation system performance variable $(\mathrm{Y})$ of 0.750 or $75 \%$.
\end{abstract}

Keywords: Irrigation System Performance, MASSCOTE, Path Analysis, Rapid Appraisal Procedure (RAP)

Abstrak: Penilaian kinerja berdasarkan Permen PUPR No. 12/PRT/2015 merupakan suatu indikasi dalam rangka menggambarkan suatu pengelolaan sistem irigasi, dilakukan terhadap 6 (enam) parameter yaitu; Prasarana Fisik, Produktivitas Tanam, Sarana Penunjang, Organisasi Personalia, Dokumentasi dan Perkumpulan Petani Pemakai Air (P3A), sedangkan pendekatan Metode MASSCOTE dilakukan dengan evaluasi Rapid Appraisal Procedure (RAP) yang merupakan seperangkat prosedur sistematis untuk mendiagnosa hambatan, kinerja dan tingkat layanan dalam sistem irigasi terhadap 4 (empat) indikator utama yaitu; Indikator Pelayanan, Indikator P3A, Indikator SDM Operator, dan Indikator Modernisasi Operasi Saluran. Penilaian 
kinerja dilakukan melalui survei terhadap petugas OP irigasi dan petani P3A yang menunjukkan indeks kinerja sebesar 64,22\% atau kategori Kurang Baik terhadap kinerja Operasi dan Pemeliharaan berdasarkan Permen PUPR No. 12/PRT/2015, sedangkan indeks kinerja sebesar 2,99 berdasarkan Metode MASSCOTE dengan evaluasi RAP menunjukkan Level of Service pada kategori Kurang Baik terhadap kinerja Operasi Saluran dan Pelayanan Irigasi. Berdasarkan analisis jalur didapatkan pengaruh signifikan secara bersama variabel indikator utama $X_{1}, X_{2}, X_{3}$ dan $X_{4}$ terhadap variabel kinerja sistem irigasi (Y) sebesar 0,750 atau $75 \%$.

Kata kunci: Analisis Jalur, Kinerja Sistem Irigasi, MASSCOTE, Rapid Appraisal Procedure (RAP)

\section{Pendahuluan}

Bidang pertanian merupakan salah satu bidang yang berperan penting untuk menambah ekonomi nasional sebab banyak penduduk yang bergantung dari hasil pertanian dimana produksi tersebut digunakan untuk dapat memenuhi kebutuhan sehari-hari. Oleh sebab itu adanya lahan untuk pertanian sangat penting dalam memenuhi kebutuhan pangan penduduk secara jangka panjang [1].

Pada Daerah Irigasi Makam Sukowono sering timbul beberapa masalah pada saat proses pengairan berlangsung mulai dari tempat pengambilan air sampai penyaluran ke petak-petak sawah pertanian. Hal itu dapat dilihat dari jumlah debit yang masuk belum sesuai dengan debit yang keluar. Ketersediaan air irigasi yang baik berhubungan erat dengan faktor-faktor berikut yaitu struktur bangunan bendung harus kuat dan baik, saluran sekunder dan saluran tersier tidak mengalami perembesan, saluran irigasi tidak boleh ada penumpukan sedimen, Penjaga Pintu Air (PPA) maupun keadaan Perkumpulan Petani Pemakai Air (P3A) harus berperan aktif dalam menjaga jaringan irigasi. Karena jika ketersediaan air kurang dapat menghambat produktiftas lahan pertanian sehingga akan menurunkan hasil pertanian. Pemeliharaan jaringan irigasi ini menjadi sangat penting karena merupakan suatu upaya untuk menjaga jaringan irigasi supaya fungsinya menjadi berkelanjutan dan mempertahankan kelestariannya.

Tujuan melakukan penelitian ini adalah untuk mengetahui nilai indeks kinerja sistem irigasi berdasarkan Permen PUPR No.12/PRT/M/2015 serta pendekatan Metode MASSCOTE [2]. Dari Metode MASSCOTE akan dilakukan suatu permodelan matematika guna menganalisis keterkaitan variabel indikator utama terhadap kinerja sistem irigasi pada Daerah Irigasi Makam Sukowono.

\section{Bahan dan Metode}

\subsection{Bahan}

Studi ini membutuhkan data-data yang mendukung dalam pengerjaan. Data yang dimaksud adalah data primer dan data sekunder. Data primer yaitu sebuah data hasil pengamatan langsung di lapangan meliputi data bangunan utama, data saluran pembawa, data bangunan bagi/sadap, data saluran pembuang dan data bangunan pada saluran pembuang.

Data sekunder merupakan data-data dari suatu lembaga atau instansi terkait dan juga dari kutipan sumber yang sebenarnya dapat dipertanggung jawabkan. Dimana data ini meliputi data inventarisasi, skema jaringan irigasi, peta-peta dan dokumentasi lapangan.

Alat bantu yang digunakan dalam studi ini antara lain:

- Perangkat lunak Microsoft Exel untuk menghitung indeks kinerja pada Daerah Irigasi Makam Sukowono berdasarkan Permen PUPR No.12/PRT/M/2015. 
- Pengujian kuisioner, input data dari hasil rekapitulasi Metode MASSCOTE.

- Perangkat lunak SPSS 22 untuk menghitung Path Analysis.

\subsubsection{Lokasi Studi}

Pada penelitian ini daerah yang di kaji adalah Daerah Irigasi Makam Sukowono yang berada di Desa Sukowono yang merupakan salah satu desa di Kecamatan Sukowono dengan luasan 540 Ha dari total luas Kecamatan Sukowono yaitu seluas 4.355 Ha. Kecamatan Sukowono mempunyai luas wilayah 44,04 $\mathrm{km}^{2}$ yang teletak pada perbatasan wilayah administratif Kabupaten Probolinggo, Kabupaten Bondowoso, Kabupaten Lumajang, dan Kabupaten Banyuwangi. Berikut adalah peta Desa Sukowono [3].

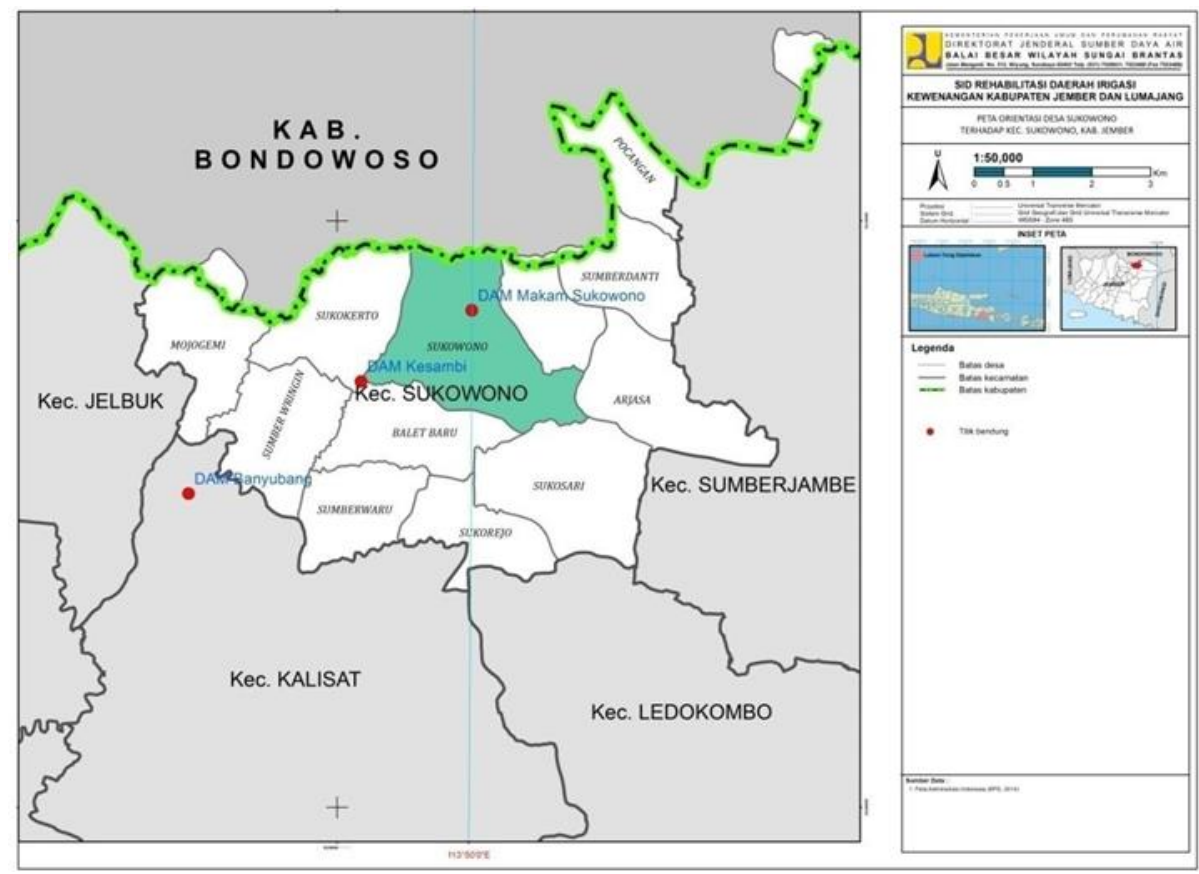

Gambar 1: Peta Desa Sukowono

\subsection{Metode}

\subsubsection{Permen PUPR Nomor 12/PRT/M/2015 tentang Pedoman Operasi dan Pemeliharaan Jaringan Irigasi}

Di dalam Peraturan Menteri Pekerjaan Umum Nomor 12/PRT/M/2015 menerangkan jika untuk menilai kinerja sistem irigasi didasarkan dengan 6 (enam) parameter. Parameter yang dinilai adalah parameter prasarana fisik, produktivitas tanam, sarana penunjang, organisasi personalia, dokumentasi, dan Perkumpulan Petani Pemakai Air (P3A) [4].

Dalam evaluasi kinerja irigasinya dilaksanakan setiap tahun. Penilaiannya merupakan penjumlahan nilai seluruh parameter penilaian dengan angka dari 0 sampai 100. Berikut kategori penilaiannya :

1. Baik Sekali = $=80 \%-100 \%$

2. Baik $=70 \%-79 \%$

3. Kurang \& perlu perhatian $\quad=55 \%-69 \%$

4. Jelek \& perlu Perhatian $\quad=<55 \%$

\subsubsection{MASSCOTE (Mapping Sistem and Service for Cannal Operation Technique)}

Metode MASSCOTE adalah suatu proses pengambilan keputusan untuk mengelola dan 
menyediakan keseimbangan yang memadai pada pasokan air dan permintaan air. Dalam urutan untuk memberi informasi kepada pembuat keputusan, penilaian kondisi dasar sangatlah penting. Solusi pengelolaan irigasi yang baik merupakan salah satu bentuk usaha yang dihasilkan dari Metode MASSCOTE. [5]

Metode MASSCOTE memiliki tujuan untuk mendapatkan solusi layanan dan operasi bagi pengguna air irigasi yang ikut berpartisipasi dalam memutuskan kebijakan pengelolaan air untuk mencapai tigkat layanan yang disetujui atau perlu ditingkatkan [6].

Langkah pertama dari pendekatan MASSCOTE adalah melakukan diagnosis yang memiliki peran dalam kemacetan kinerja dalam suatu sistem irigasi. Rapid Appraial Procedure (RAP) akan memberi gambaran kondisi sistem irigasi terkait dari hasil saling menilai terhadap responden petugas OP dan petani P3A [7].

Teknik Analisis Jalur (Path Analysis) digunakan untuk mengetahui berapa besar pengaruh indikator utama yang berupa indikator pelayanan irigasi, indikator P3A, indikator SDM OP, indikator modernisasi OP terhadap kinerja irigasinya [8].

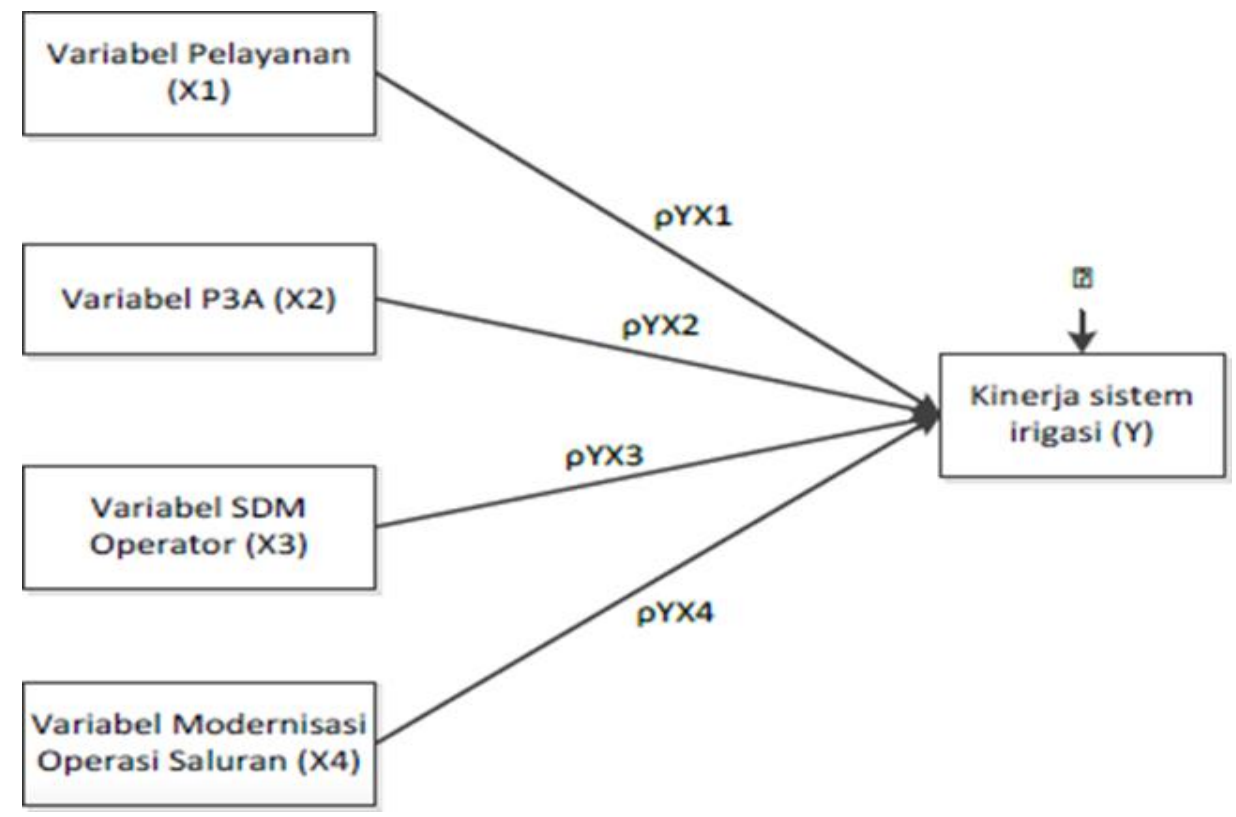

Gambar 2: Diagram Jalur Kinerja Sistem Irigasi Makam Sukowono

\subsection{Persamaan}

Analisis Jalur (Path Analysis) digunakan untuk mengetahui berapa besar pengaruh indikator utama yang berupa indikator pelayanan irigasi, indikator P3A, indikator SDM OP, indikator modernisasi OP terhadap kinerja sistem irigasi, berikut persamaannya jalurnya:

$$
Y=\text { pyx }_{1} X_{1}+\text { pyx }_{2} X_{2}+p y x_{3} X_{3}+\text { pyx } x_{4} X_{4} \quad \text { Pers. } 1
$$

Keterangan:

$\mathrm{Y}=$ Kinerja sistem irigasi

$\mathrm{X}_{1}=$ Indikator Pelayanan

$\mathrm{X}_{2}=$ Indikator Petani P3A

$\mathrm{X}_{3}=$ Indikator SDM Operator

$\mathrm{X}_{4}=$ Indikator Modernisasi Operasi saluran

$\rho=$ Koefisien jalur antara variabel akibat dan variabel penyebab 


\subsection{Langkah Penelitian}

Penilaian dilakukan berdarkan Peraturan Menteri PUPR Nomor 12/PRT/M/2015 dimana hal yang pertama harus dilakukan adalah mengumpulkan data primer dan data sekunder [9]. Pada Daerah Irigasi Makam Sukowono yang dinilai hanya saluran sekunder dan tersier karena Daerah Irigasi Makam Sukowono tidak memiliki saluran primer. Setelah proses mengumpulkan data selanjutnya akan dilakukan analisis data. Pada penilaian berdasarkan Peraturan Menteri PUPR Nomor 12/PRT/M/2015 utuk menghitung kinerja sistem irigasinya perlu menganalisis 6 (enam) parameternya [10]. Selanjutnya dilakukan penilaian suatu kinerja irigasi yang didukung oleh Metode MASSCOTE yang dilakukan dengan pengamatan langsung di lapangan, wawancara dan kuesioner. Hasil analisis dan pembahasan diperoleh kesimpulan.

\section{Hasil dan Pembahasan}

\subsection{Penilaian Kinerja Sistem Irigasi Berdasarkan Permen PUPR No. 12/PRT/M/2015}

Tabel 1: Rekap Penelitian Kinerja Sistem Irigasi Berdasarkan Permen PUPR No.12/PRT/M/2015

\begin{tabular}{|c|c|c|c|}
\hline Uraian & $\begin{array}{c}\text { Nilai } \\
\text { Bobot }\end{array}$ & $\begin{array}{c}\text { Nilai } \\
\text { Kondisi } \\
\text { Fisik } \\
\text { (NKF) } \\
3\end{array}$ & $\begin{array}{c}\text { Nilai } \\
\text { Kondisi } \\
\text { Bobot } \\
(\mathrm{NKB}) \\
4=(2 \mathrm{X} 3) / 100\end{array}$ \\
\hline I. PRASARANA FISIK & 45,00 & & 27,59 \\
\hline 1. Bangunan Utama & 13,00 & & 8,45 \\
\hline 1.1. Bendung & 4,00 & & 2,92 \\
\hline a. Mercu & 0,80 & 90,00 & 0,72 \\
\hline b. Sayap & 0,60 & 90,00 & 0,54 \\
\hline c. Lantai bendung & 0,80 & 80,00 & 0,64 \\
\hline d. Tanggul penutup & 0,80 & 90,00 & 0,72 \\
\hline e. Jembatan & 0,20 & 70,00 & 0,14 \\
\hline f. Papan untuk operasi & 0,40 & 0,00 & 0,00 \\
\hline g. Mistar ukur & 0,20 & 80,00 & 0,16 \\
\hline h. Pagar pengaman & 0,20 & 0,00 & 0,00 \\
\hline $\begin{array}{l}\text { 1.2. Pintu-pintu dalam bendung dan roda gigi dapat } \\
\text { dioperasikan. }\end{array}$ & 7,00 & & 4,55 \\
\hline a. Pintu pengambilan & 3,50 & 80,00 & 2,80 \\
\hline b. Pintu penguras Bendung & 3,50 & 50,00 & 1,75 \\
\hline 1.3. Kantong lumpur\& Pintu Pengurasnya & 2,00 & & 0,98 \\
\hline a. Bangunan kantong lumpur baik & 0,70 & 80,00 & 0,56 \\
\hline b. Kantong lumpur telah di bersihkan & 0,60 & 70,00 & 0,42 \\
\hline $\begin{array}{l}\text { c. Pintu penguras \& roda gigi kantong lumpur } \\
\text { dapat dioperasikan }\end{array}$ & 0,70 & 0,00 & 0,00 \\
\hline 2. Saluran Pembawa & 10,00 & & 6,80 \\
\hline $\begin{array}{l}\text { 2.1. Kapasitas tiap saluran cukup untuk membawa } \\
\text { debit kebutuhan /rencana }\end{array}$ & 5,00 & 80,00 & 4,00 \\
\hline $\begin{array}{l}\text { 2.2. Tinggi tanggul cukup untuk menghindari limpahan } \\
\text { setiap saat selama pengoperasian }\end{array}$ & 2,00 & 80,00 & 1,60 \\
\hline 2.3. Semua perbaikan saluran telah selesai & 3,00 & 40,00 & 1,20 \\
\hline 3. Bangunan Pada Saluran Pembawa & 9,00 & & 8,24 \\
\hline $\begin{array}{l}\text { 3.1. Bangunan pengatur (Bagi/Bagi Sadap/Sadap) } \\
\text { lengkap dan berfungsi }\end{array}$ & 2,00 & & 1,10 \\
\hline $\begin{array}{l}\text { a. Setiap saat dan setiap bangunan pengatur } \\
\text { perlu saluran induk dan sekunder }\end{array}$ & 1,00 & 60,00 & 0,60 \\
\hline b. Pada setiap sadap tersier & 1,00 & 50,00 & 0,50 \\
\hline
\end{tabular}




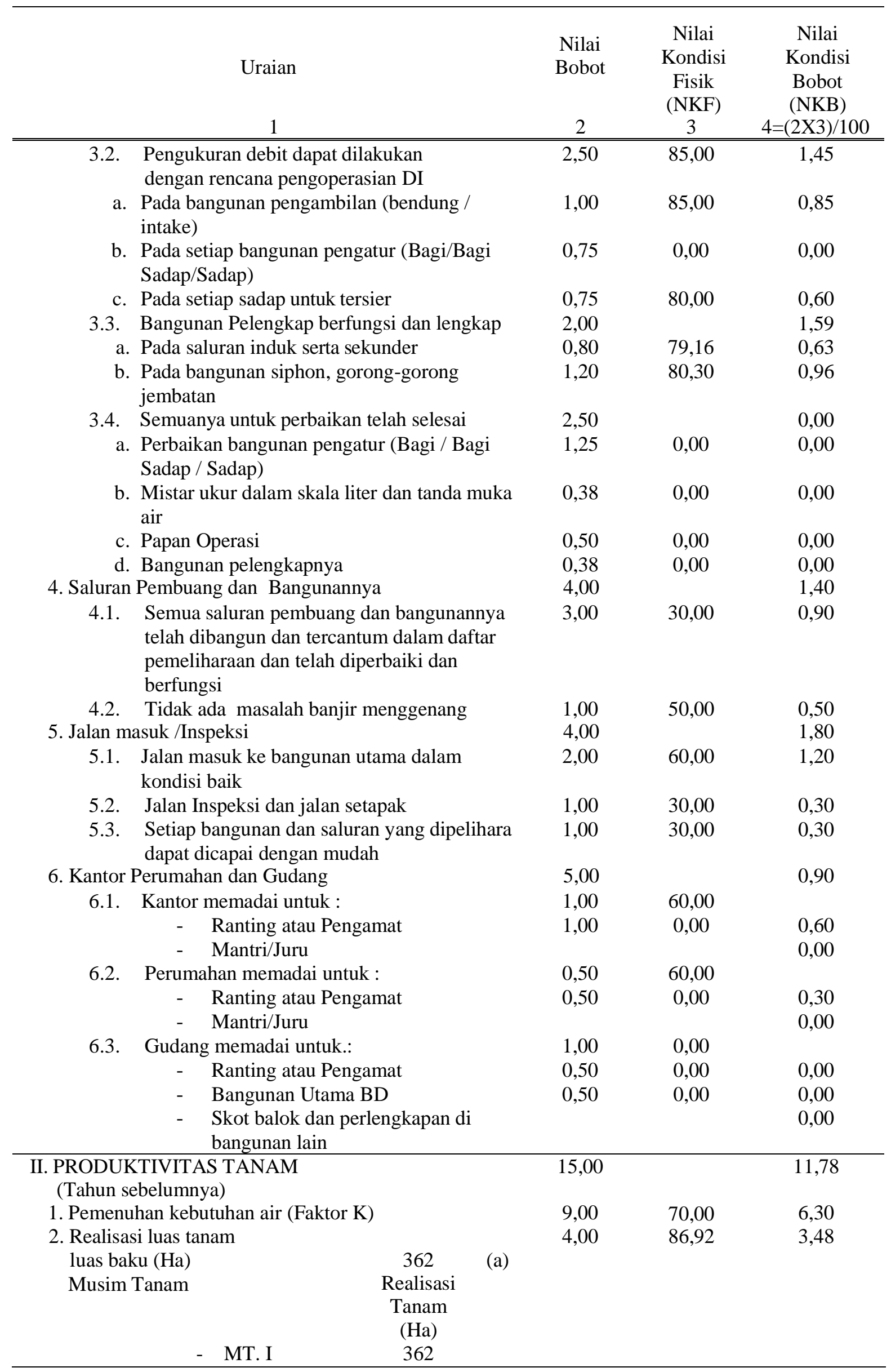




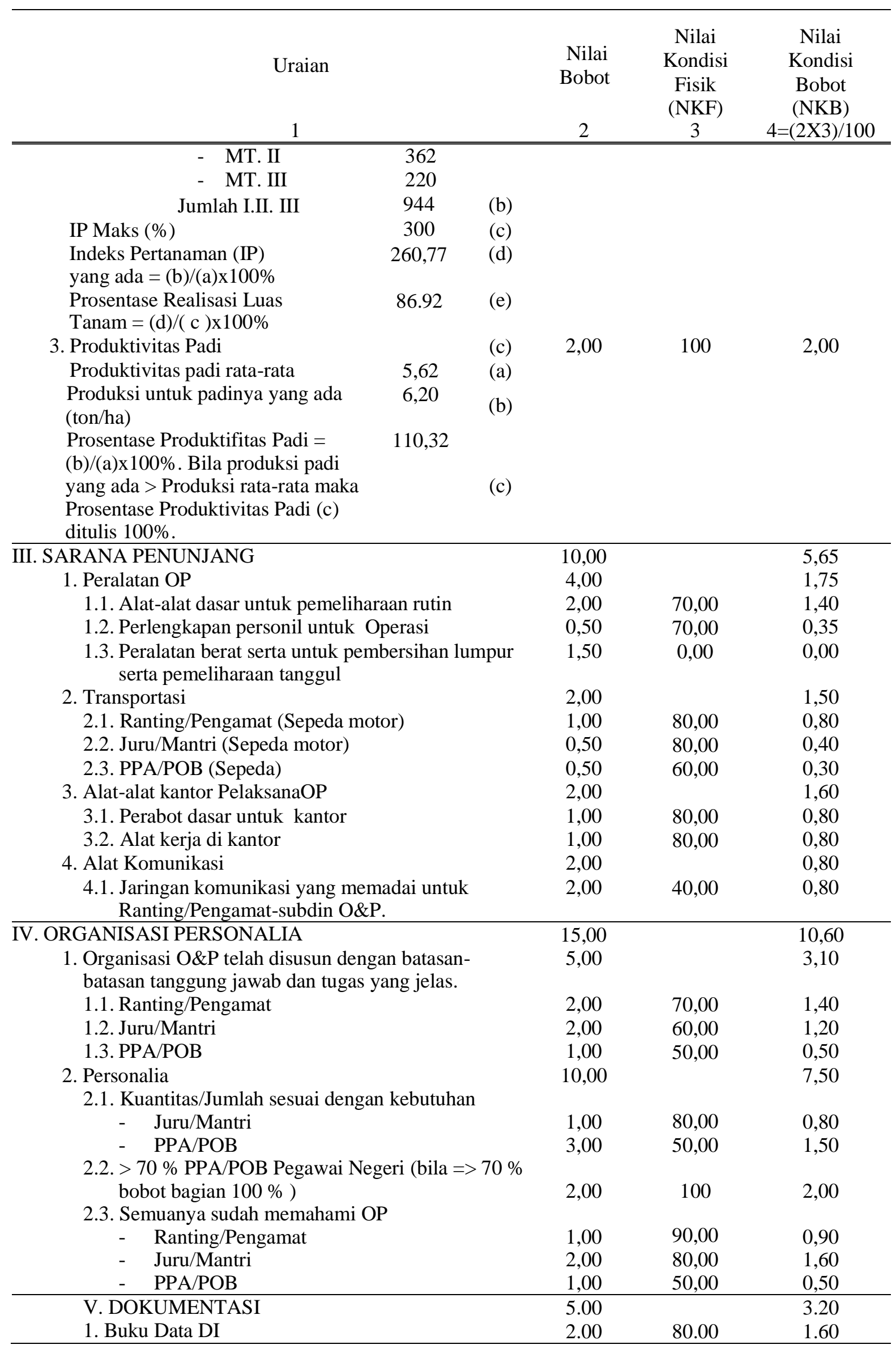




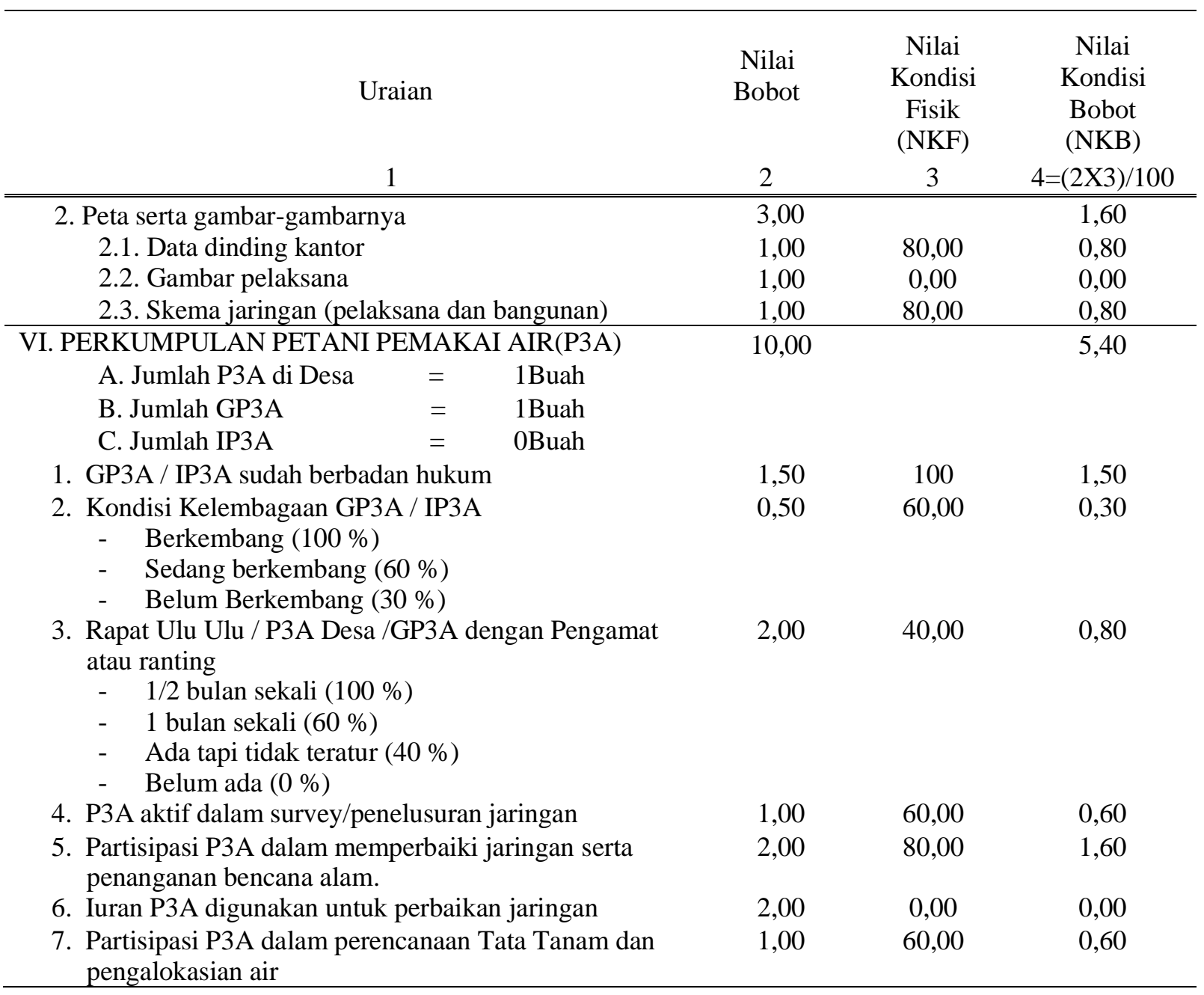

Tabel 2: Rekap Penilaian Indeks Kinerja Sistem Irigasi berdasarkan Permen PUPR No 12/PRT/M/2015

\begin{tabular}{|c|c|c|c|}
\hline No & Parameter Penilaian & $\begin{array}{c}\text { Hasil } \\
\text { Perhitungan } \\
\%\end{array}$ & $\begin{array}{c}\text { Maks } \\
\% \\
\end{array}$ \\
\hline I & Prasarana Fisik & 27.59 & 45 \\
\hline II & Produktivitas tanam & 11.78 & 15 \\
\hline III & Sarana Penunjang & 5.65 & 10 \\
\hline IV & Organisasi Personalia & 10.60 & 15 \\
\hline $\mathrm{V}$ & Dokumentasi & 3.20 & 5 \\
\hline VI & P3A & 5.40 & 10 \\
\hline & JUMLAH & 64.22 & 100 \\
\hline
\end{tabular}

Nilai sebesar $64.22 \%$ (nilai maksimum 100) dalam \%. termasuk pada kategori kinerja kurang dan perlu perhatian. Dari hasil perhitungan. parameter yang paling berkontribusi menyebabkan kinerja dalam kondisi kurang dan perlu perhatian adalah pada parameter P3A. Sarana Penunjang. dan Prasarana Fisik.

Pada parameter P3A aspek yang berkontribusi paling banyak menyebabkan kinerja dalam kondisi kurang adalah karena anggota P3A tidak pernah melakukan iuran P3A yang digunakan untuk perbaikan jaringan serta tidak mempunyai jadwal pertemuan rapat secara rutin. Berdasarkan dari hasil wawancara rapat hanya dilakukan saat membahas kebutuhan air serta pengalokasian air. 
Pada parameter sarana penunjang aspek yang berkontribusi paling banyak dalam menyebabkan kinerja dalam kondisi kurang adalah peralatan berat untuk pembersihan lumpur dan pemeliharaan tanggul. Selain itu adalah kurangnya jaringan komunikasi yang memadai untuk Ranting/Pengamat. dikarenakan tidak adanya prasana jaringan komunikasi dari Dinas PU Bina Marga \& SDA Kab. Jember.

Pada parameter prasarana fisik aspek yang paling berkontribusi menyebabkan kinerja dalam kondisi kurang adalah aspek kantor. perumahan dan gudang.. Hal ini disebabkan karena kantor dan perumahan hanya tersedia untuk ranting/pengamat. sedangkan untuk juru tidak terdapat kantor serta perumahan. Kondisi kantor dan perumahan dalam kondisi kurang baik. terdapat beberapa keretakan pada dinding kantor. terdapat kaca jendela yang lepas serta halaman kantor yang tidak terawat.

\subsection{Penilaian Kinerja Sistem Irigasi Berdasarkan Metode MASSCOTE}

Berikut adalah data hasil evaluasi dengan pendekatan Rapid Appraisal Procedure (RAP). Data ini didapatkan dari kuesioner untuk melakukan cross assesment/saling menilai antar responden dalam pengelolaan irigasi pada Daerah Irigasi Makam Sukowono.

Tabel 3: Rekap Penilaian Indeks Kinerja sistem Irigasi Berdasarkan Metode MASSCOTE

\begin{tabular}{|c|c|c|c|c|c|}
\hline Nama Indikator Utama & $\begin{array}{l}\text { Nilai } \\
(1-4)\end{array}$ & $\begin{array}{l}\text { Sumber } \\
\text { Informasi } \\
\text { Data }\end{array}$ & $\begin{array}{c}\text { Nilai } \\
\text { Maksimal }\end{array}$ & $\begin{array}{c}\text { Nilai } \\
\text { Survei } x \\
\text { Bobot }\end{array}$ & $\begin{array}{l}\text { Total } \\
\text { Nilai } \\
\text { Bobot }\end{array}$ \\
\hline \multicolumn{6}{|c|}{ Pelayanan PesananPengguna Air Irigasi } \\
\hline $\begin{array}{l}\text { Unit individu misal sawah bagaimana } \\
\text { layanan pengiriman airnya? Apakah } \\
\text { teralisasi? }\end{array}$ & 3.05 & $\begin{array}{l}\text { Pengiriman } \\
\text { Terakhir }\end{array}$ & 4.00 & 33.58 & 11 \\
\hline $\begin{array}{l}\text { Untuk sawah apakah ada rencana } \\
\text { layanan pengiriman air }\end{array}$ & 3.31 & $\begin{array}{l}\text { Pertanyaan } \\
\text { Kantor }\end{array}$ & 4.00 & 36.41 & 11 \\
\hline $\begin{array}{l}\text { Pada sawah paling jauh apakah } \\
\text { pelayanan air terealisasi saat sistem } \\
\text { diperasikan oleh operator? }\end{array}$ & 3.08 & $\begin{array}{l}\text { Pengiriman } \\
\text { Terakhir }\end{array}$ & 4.00 & 52.36 & 17 \\
\hline $\begin{array}{l}\text { Untuk sawah terjauh apakah ada } \\
\text { rencana layanan pengiriman air oleh } \\
\text { operator? }\end{array}$ & 3.21 & $\begin{array}{l}\text { Pertanyaan } \\
\text { Kantor }\end{array}$ & 4.00 & 54.51 & 17 \\
\hline $\begin{array}{l}\text { Apakah ada pesanan air dari petani atau } \\
\text { pengguna air yang dioperasikan oleh } \\
\text { operator? }\end{array}$ & 3.26 & $\begin{array}{l}\text { Pengiriman } \\
\text { Terakhir }\end{array}$ & 4.00 & 13.04 & 4 \\
\hline Total Nilai I & 15.91 & & 20.00 & & \\
\hline \multicolumn{6}{|c|}{ Saluran Sekunder } \\
\hline $\begin{array}{l}\text { Apakah tersedia Handware atau } \\
\text { perangkat keras untuk mengukur di } \\
\text { saluran sekunder? }\end{array}$ & 3.03 & $\begin{array}{c}\text { Saluran } \\
\text { Tingkat II }\end{array}$ & 4.00 & 6.07 & 2 \\
\hline $\begin{array}{l}\text { Apakah tersedia alat komunikasi untuk } \\
\text { operator pengelola irigasi pada saluran } \\
\text { sekunder? }\end{array}$ & 3.05 & $\begin{array}{c}\text { Saluran } \\
\text { Tingkat II }\end{array}$ & 4.00 & 33.51 & 11 \\
\hline $\begin{array}{l}\text { Bagaimana kondisi umum pada saluran } \\
\text { sekunder? }\end{array}$ & 2.61 & $\begin{array}{l}\text { Saluran } \\
\text { Tingkat II }\end{array}$ & 4.00 & 13.07 & 5 \\
\hline $\begin{array}{l}\text { Apakah pengoperasian bangunan pada } \\
\text { saluran sekunder berjalan dengan baik? }\end{array}$ & 3.00 & $\begin{array}{c}\text { Saluran } \\
\text { Tingkat II }\end{array}$ & 4.00 & 15.00 & 5 \\
\hline Total Nilai II & 11.69 & & 16.00 & & \\
\hline \multicolumn{6}{|c|}{ Saluran Tersier } \\
\hline $\begin{array}{l}\text { Apakah tersedia Handware atau } \\
\text { perangkat keras untuk mengukur di } \\
\text { saluran tersier? }\end{array}$ & 2.66 & $\begin{array}{l}\text { Saluran } \\
\text { Tingkat III }\end{array}$ & 4.00 & 5.32 & 2 \\
\hline $\begin{array}{l}\text { Bagaimana kondisi bangunan pembagi di } \\
\text { saluran tersier? }\end{array}$ & 2.61 & $\begin{array}{l}\text { Saluran } \\
\text { Tingkat III }\end{array}$ & 4.00 & 7.82 & 3 \\
\hline
\end{tabular}




\begin{tabular}{|c|c|c|c|c|c|}
\hline Nama Indikator Utama & $\begin{array}{l}\text { Nilai } \\
(1-4)\end{array}$ & $\begin{array}{l}\text { Sumber } \\
\text { Informasi } \\
\text { Data }\end{array}$ & $\begin{array}{c}\text { Nilai } \\
\text { Maksimal } \\
\end{array}$ & $\begin{array}{l}\text { Nilai } \\
\text { Survei x } \\
\text { Bobot }\end{array}$ & $\begin{array}{l}\text { Total } \\
\text { Nilai } \\
\text { Bobot }\end{array}$ \\
\hline $\begin{array}{l}\text { Apakah tersedia alat komunikasi untuk } \\
\text { operator pengelola irigasi pada saluran } \\
\text { tersier? }\end{array}$ & 3.00 & $\begin{array}{c}\text { Saluran } \\
\text { Tingkat III }\end{array}$ & 4.00 & 33.00 & 11 \\
\hline $\begin{array}{l}\text { Bagaimana kondisi umum pada saluran } \\
\text { tersier? }\end{array}$ & 2.62 & $\begin{array}{c}\text { Saluran } \\
\text { Tingkat III }\end{array}$ & 4.00 & 13.10 & 5 \\
\hline $\begin{array}{l}\text { Apakah pengoperasian bangunan pada } \\
\text { saluran tersier berjalan dengan baik? }\end{array}$ & 3.00 & $\begin{array}{c}\text { Saluran } \\
\text { Tingkat III }\end{array}$ & 4.00 & 15.00 & 5 \\
\hline Total Nilai III & 13.89 & & 20.00 & & \\
\hline \multicolumn{6}{|l|}{ SDM Pengelola Irigasi dan P3A/GP3A } \\
\hline $\begin{array}{l}\text { Bagaimana kondisi karyawan/operator } \\
\text { pengelola irigasi? }\end{array}$ & 3.00 & Karyawan & 4.00 & 28.50 & 9.50 \\
\hline $\begin{array}{l}\text { Bagimana kondisi keanggotaan } \\
\text { WUA/GP3A? }\end{array}$ & 3.31 & P3A & 4.00 & 21.54 & 6.50 \\
\hline $\begin{array}{l}\text { Apakah mobilitas serta staf operasinya } \\
\text { baik? }\end{array}$ & 3.01 & $\begin{array}{l}\text { Pertanyaan } \\
\text { Kantor }\end{array}$ & 4.00 & 3.01 & 1.00 \\
\hline $\begin{array}{l}\text { Apakah tersedia computer untuk } \\
\text { mencatat manajemen? }\end{array}$ & 3.03 & $\begin{array}{l}\text { Pertanyaan } \\
\text { Kantor }\end{array}$ & 4.00 & 3.03 & 1.00 \\
\hline $\begin{array}{l}\text { Apakah tersedia computer untuk } \\
\text { mengontrol saluran? }\end{array}$ & 3.24 & $\begin{array}{l}\text { Pertanyaan } \\
\text { Kantor }\end{array}$ & 4.00 & 3.24 & 1.00 \\
\hline Total Nilai IV & 15.60 & & 20.00 & & \\
\hline \multicolumn{6}{|c|}{ Indikator Modernisasi Operasi Saluran Irigasi } \\
\hline $\begin{array}{l}\text { Apakah kemampuan (eksisting) dari } \\
\text { layanan pengiriman air untuk } \\
\text { mendukung modernisasi irigasi berjalan } \\
\text { dengan baik? }\end{array}$ & 2.63 & $\mathrm{n} / \mathrm{a}$ & 4.00 & 7.88 & 3 \\
\hline $\begin{array}{l}\text { Apakah perlu melakukan perubahan } \\
\text { operasi saluran diperlukan agar dapat } \\
\text { mendukung } \\
\text { modernisasi irigasinya? }\end{array}$ & 3.00 & $\mathrm{n} / \mathrm{a}$ & 4.00 & 6.00 & 2 \\
\hline \multirow{4}{*}{$\begin{array}{c}\text { Total Nilai V } \\
\text { Total Nilai (I+II+III+IV+V) } \\
\text { Rata-rata Prosentase (\%) Indikator } \\
\text { Internal } \\
\text { Nilai Mutlak (Serfice of level) }\end{array}$} & 5.63 & & 8.00 & & \\
\hline & 62.72 & & 84.00 & & \\
\hline & 0.746 & & & & \\
\hline & 2.99 & & & & \\
\hline
\end{tabular}

Berdasarkan Metode MASSCOTE dengan evaluasi RAP penilaian kinerja Daerah Irigasi Makam Sukowono menunjukkan indeks kinerja sebesar 2.99. Level of Service dalam Metode MASSCOTE memberikan kategori sebagai berikut :
1) Sangat Baik =4
2) Baik = 3-3.9
3) Kurang Baik $=2-2.9$
4) Buruk = $1-1.9$

Maka berdasarkan kategori tersebut indeks kinerja Daerah Irigasi Makam Sukowono berada pada kategori Kurang Baik. 


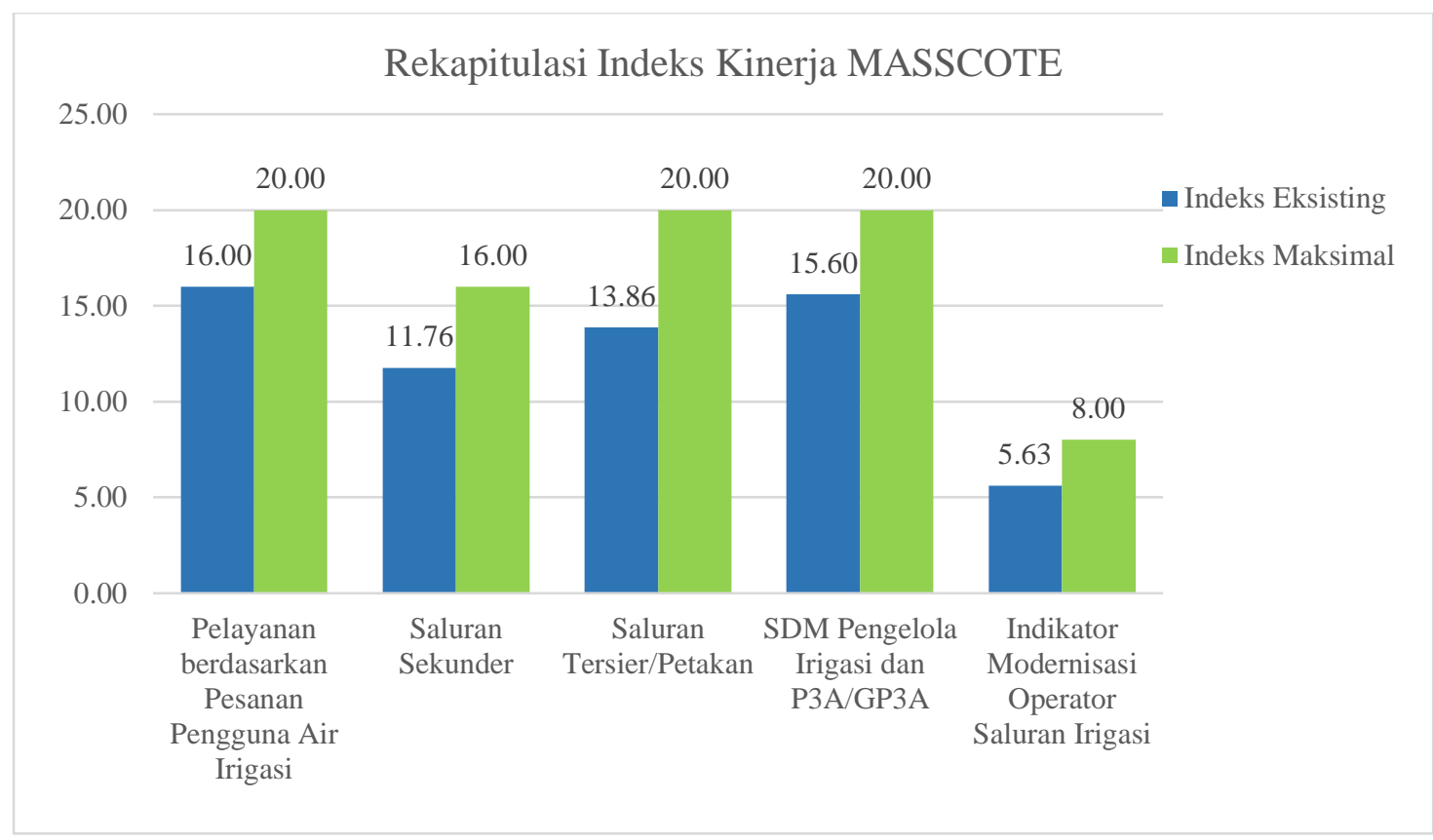

Gambar 3: Rekapitulasi Indeks Kinerja MASSCOTE

Pada penialain kondisi kinerja sistem irigasi berdasarkan Metode MASSCOTE dengan evaluasi RAP aspek yang berkontribusi menyebabkan kinerja dalam kondisi kurang baik adalah pada indikator saluran sekunder. saluran tersier. dan indikator modernisasi operasi saluran.

Pada indikator saluran sekunder aspek yang berkontribusi paling banyak menyebabkan kinerja dalam kondisi kurang adalah pada aspek ketersediaan peralatan serta staf untuk pemeliharaan saluran sekunder kurang memadai.

Pada indikator saluran tersier aspek yang berkontribusi menyebabkan kinerja dalam kondisi kurang adalah pada aspek pemeliharaan pada saluran tersier. Aspek lainnya adalah kondisi umum tingkat saluran tersier dimana ketersediaan peralatan yang digunakan untuk pemeliharaan saluran tersier kurang dan staf untuk mempertahankan kondisi saluran tersier juga kurang. Serta indikator lain yang mempengaruhi nilai kinerja kurang adalah hardware/perangkat keras bangunan pengukur dimana tingkat pemeliharaan jaringan ukurnya kurang baik.

Pada indikator modernisasi operasi saluran irigasi aspek yang berkontribusi menyebabkan kinerja dalam kondisi kurang adalah pada aspek kemampuan (eksisting) layanan pengiriman air untuk mendukng modernisasi irigasi. dimana keandalan pengiriman air masuk dalam katagori kurang.

Karena ketiga indikator yaitu indikator saluran sekunder. salran terier. dan modernisasi operasi saluran irigasi memiliki nilai mutlak (level of service) kurang dari 3. maka mempengaruhi pada kondisi kinerja sistem irigasi dengan pendekatan metode MASSCOTE dengan evaluasi RAP menunjukkan indeks kinerja sebesar 2.99. Dimana nilai tersebut masuk pada kategori kurang baik.

Hal ini mendukung nilai kinerja sistem irigasi berdasarkan Peraturan Menteri Pekerjaan Umum No.12/PRT/M/2015 dimana salah satu parameter yang menyebabkan nilai kinerja sistem irigasi kurang dan perlu perhatian adalah sarana penunjang. prasarana fisik. dan P3A.

\subsection{Pemodelan dengan Analisis Jalur (Path Analysis)}

Analisis Jalur atau Path Analysis dilakukan untuk memberitahu berapa besar pengaruh dari indikator utama terhadap kinerja sistem irigasi. Berikut merupakan rekapitulasi data ordinal jawaban responden terhadap variable indikator utama. 
Tabel 4: Rekapitulasi Data Ordinal Jawaban Responden Terhadap Variabel Indikator Utama

\begin{tabular}{cccccc}
\hline Responden & $\mathrm{X}_{1}$ & $\mathrm{X}_{2}$ & $\mathrm{X}_{3}$ & $\mathrm{X}_{4}$ & $\mathrm{Y}$ \\
\hline 1 & 22.00 & 19.00 & 13.60 & 29.50 & 28.50 \\
2 & 23.00 & 19.00 & 13.60 & 28.00 & 27.20 \\
3 & 22.10 & 20.50 & 13.80 & 28.70 & 27.40 \\
4 & 23.00 & 20.50 & 13.70 & 29.20 & 28.20 \\
5 & 22.60 & 20.00 & 13.90 & 30.20 & 28.00 \\
6 & 22.50 & 20.50 & 13.80 & 28.50 & 27.50 \\
7 & 22.00 & 20.50 & 13.90 & 29.60 & 28.40 \\
8 & 22.90 & 20.50 & 13.80 & 26.70 & 28.00 \\
9 & 23.40 & 20.50 & 13.90 & 29.00 & 28.50 \\
10 & 23.60 & 19.50 & 13.80 & 27.50 & 27.00 \\
11 & 23.00 & 19.20 & 13.70 & 27.90 & 27.00 \\
12 & 22.00 & 19.00 & 13.80 & 27.40 & 27.40 \\
13 & 22.80 & 19.00 & 13.70 & 28.50 & 27.00 \\
14 & 23.60 & 19.00 & 13.90 & 28.50 & 27.70 \\
15 & 23.80 & 20.00 & 14.10 & 27.20 & 28.20 \\
\hline
\end{tabular}

Jawaban responden diberikan skala penilaian 1 - 4 dari setiap pilihan jawaban. Setelah itu menggunakan bantuan software SPSS 22 akan diperoleh analisis data yang menghasilkan persamaan jalur sebagai berikut :

$\mathrm{Y}=-0.462 \mathrm{X}_{1}+0.584 \mathrm{X}_{2}+0.597 \mathrm{X}_{3}-0.440 \mathrm{X}_{4}$. dengan $\mathrm{R}^{2} 0.75$ atau $75 \%$.

Persamaan tersebut dapat diartikan bahwa keempat indikator utamanya berpengaruh secara simultan yang langsung mempengaruhi Kinerja Sistem Irigasi $(\mathrm{Y})$ sebesar $0.750=75 \%$.

\section{Kesimpulan}

Berdasarkan hasil analisis dan pembahasan dapat diperoleh hasil kesimpulan sebagai berikut:

1. Kinerja sistem irigasi Makam Sukowono berdasarkan Permen PU No.12/ PRT/M/2015 menunjukkan nilai sebesar $64.22 \%$ (nilai maksimum 100) dalam \%. termasuk pada kategori Kurang dan Perlu Perhatian. Parameter yang paling berkontribusi menyebabkan kinerja dalam kondisi kurang dan perlu perhatian adalah pada parameter P3A. Sarana Penunjang. dan Prasarana Fisik.

2a. Kinerja sistem irigasi berdasarkan Metode MASSCOTE dengan evaluasi RAP menunjukkan nilai 2.99 (nilai maksimum 4) dalam level of service termasuk dalam kategori Kurang. Aspek yang berkontribusi menyebabkan kinerja dalam kondisi kurang baik adalah pada indikator saluran sekunder. saluran tersier. dan indikator modernisasi operasi saluran irigasi. Hal ini disebabkan karena ketiga indikator memiliki level of service kurang dari 3. Dari perhitungan Analisis Jalur kontribusi Indikator Pelayanan Irigasi $\left(\mathrm{X}_{1}\right)$. Indikator P3A $\left(\mathrm{X}_{2}\right)$. Indikator SDM Petugas OP $\left(\mathrm{X}_{3}\right)$. dan Indikator Modernisasi OP $\left(\mathrm{X}_{4}\right)$ berpengaruh secara simultan terhadap Kinerja Sistem Irigasi (Y) sebesar $0.750=75 \%$. Dari analisis yang telah dilakukan. didapatkan permodelan matematika sebagai berikut: $\mathrm{Y}=-0.462 \mathrm{X}_{1}+0.584 \mathrm{X}_{2}+0.597 \mathrm{X}_{3}-0.440 \mathrm{X}_{4}$. dengan $\mathrm{R}^{2} 0.750$ atau $75 \%$.

b. Hal ini mendukung nilai kinerja sistem irigasi berdasarkan Peraturan Menteri Pekerjaan Umum No.12/PRT/M/2015 dimana salah satu parameter yang menyebabkan nilai kinerja sistem irigasi kurang dan perlu perhatian adalah sarana penunjang. prasarana fisik. dan P3A. 


\section{Daftar Pustaka}

[1] I. S. Mulyadi, S. Natasaputra, Penilaian Kinerja Irigasi Berdasarkan Pendekatan Permen PU NO. 32/2007 Dan Metode MASSCOTE Dengan Evaluasi Rapid Appraisal Procedure (RAP) Di Daerah Irigasi Barubug. Jawa Barat: Institut Teknologi Bandung, 2014.

[2] C. Mubarok, S. I. Wahyudi, G. D. Asfari, Penilaian Kinerja Irigasi Berdasarkan Pendekatan Permen PUPR No. 12/PRT/M/2015 Dan Metode MASSCOTE Dengan Evaluasi Rapid Appraisal Procedure (RAP) Di Daerah Irigasi Glapan. Jawa Tengah: Universitas Sultan Agung Semarang. 2016.

[3] Dinas PU Bina Marga \& SDA Kabupaten Jember. Jember: 2019.

[4] Pemerintah Republik Indonesia, Peraturan Menteri Pekerjaan Umum dan Perumahan Rakyat Nomor 12/PRT/M/2015 tentang Eksploitasi dan Pemeliharaan. Jakarta: Pemerintah Republik Indonesia, 2015.

[5] Renault, Daniel et al, Modernizing Irrigation Management - The MASSCOTE Approach. Rome Italy: FAO Irrigation dan Drainage Paper, 2007.

[6] Winardi, Kajian Kinerja Sistem Irigasi Di Daerah Irigasi Pandrah Kabupaten Bireuen. Banda Aceh: Universitas Syiah Kuala, 2019.

[7] Burt, Charles Dr, Rapid Appraisal Process (RAP) and Benchmarking Explanationand Tools. USA: ITRC Cal Poly California, 2001.

[8] Riduwan, E. A. Kuncoro, Cara Menggunakan dan Memaknai Analisis Jalur (Path Analysis). Bandung: Alfabeta. 2010.

[9] Rahajeng, E. A. Tri, Kinerja Sistem Irigasi Daerah Irigasi (DI) Krisak Kabupaten Wonogiri. Jawa Tengah: Universitas Sebelas Maret, 2012.

[10] S. M. Fachrie,M. Achmad, Samsuar, Penilaian Kinerja Sistem Irigasi Utama Daerah Irigasi Bantimurung Kabupaten Maros. Sulawesi Selatan: Universitas Hasanudin, 2019. 